\title{
Bernardo de Balbuena: a vueltas con la épica Bernardo de Balbuena: Epic Poetry Revisited
}

TRINIDAD BARRERA

Depto. de Literatura Española e Hispanoamericana Universidad de Sevilla

C/ Palos de la Frontera s/n. Sevilla, 41004

tbarrera@us.es

Orcid ID 0000-0001-9767-9328

Resumen: Ante la necesidad de una atención crítica a un corpus de escritos considerables que incluye obras de retórica y poética y reflexiones puntuales sobre los géneros, de corta extensión y como defensa de lo que se va a escribir, se ha elegido como tema de este trabajo el prólogo a un poema épico, el Bernardo, o Victoria de Roncesvalles de Bernardo de Balbuena, en el que se aprecia la reflexión poética aplicada al género.

Palabras clave: Épica. Prólogo. Poética. Balbuena. El Bernardo.
RECIBIDO: 11 DE ENERO DE 2018 ACEPTADO: 22 DE MARZO DE 2018

\begin{abstract}
Given the need for critical attention to a corpus of considerable writings that includes works of rhetoric and poetics and specific reflections on genres, of short length and as a defense of what is going to be written, this article deals with the prologue to an epic poem, Bernardo, o Victoria de Roncesvalles by Bernardo de Balbuena, in which the poetical reflection applied to the epic genre is appreciated.
\end{abstract}

Keywords: Epic. Prologue. Poetics. Balbuena. The Bernardo. 
T odavía hoy advertimos en los estudios coloniales cómo la vida intelectual de la colonia sigue siendo bien tratada en lo que a nombres de primera fila se refiere, ya sea en el campo de las crónicas de Indias, la poesía lírica o incluso en géneros muy populares en aquellos siglos, como el teatro. Por el contrario, son preteridas de entrada las manifestaciones en prosa a las que, por escasas y no leídas en su mayoría, resulta más cómodo colgarles la etiqueta de mala calidad que entrar detenidamente en el análisis de textos como pueden ser los de Francisco Bramón o Joaquín de Bolaños.

En el panorama de las letras coloniales el estudio de la épica no había sido actualizado hasta llegar a los estudios de Davis (2000), Marrero-Fente (2002; 2017) y Firbas. Ya el mismo Marrero-Fente ha destacado el carácter fantasmal o espectral del género $(2002 ; 2017)$ y ha estudiado los modelos que lo sustentan y su evolución en los siglos XVI y XVII. Las manifestaciones culturales de la colonia con frecuencia arrojan todas ellas destellos de una conciencia criolla en formación y si bien cabe apreciar todas las matizaciones que veamos oportunas en los diversos géneros de poesía, prosa o teatro, justificadas siempre por certeras y demostrables, esto no nos debe llevar a olvidar que la formación de la cultura virreinal no es entendible sin sus modelos peninsulares y la herencia que estos aportan, auténticos referentes de la cultura letrada en la colonia, como son los modelos del Renacimiento italiano y los clásicos, a los que unos y otros se remiten. Y ello se hace aún más palpable en el modelo de la épica pues estamos de acuerdo, como dice Marrero-Fente, en que "el género épico es el discurso cultural más complejo de la temprana modernidad" $(2002,17)$.

El deseo colectivo de escribir un poema épico fue más fuerte y atractivo de lo que pudiera imaginarse, otra cosa son sus realizaciones fácticas. Poco conocido es que Francisco Bramón, en el prólogo a su novela pastoril divinizada, Los Sirgueros de la Virgen (1620) anunció:

Recibe con amor estos pensamientos, que en pago del buen hospedaje que les hicieres procuraré en breve deleitarte con los discursos del trágico soldado, y libro de los más entretenidos que haya tomado puerto y abrigo en tus piadosas manos.

De dos partos de mi entendimiento muy bien es el primogénito siga el espíritu e inclinación en esta parte, y que el segundo, siguiendo el militar estruendo, se incline a Marte. (2013, 45-46)

No tenemos noticias de la escritura de ese libro, pero ahí está la intención. No solo la prosa o la épica han sufrido desatención, otro enorme y fecundo cam- 
po ha quedado preterido en los estudios de la colonia, me refiero al universo de las teorías sobre la escritura que hallaron reflejo al otro lado del Atlántico, en la mayoría de las ocasiones al hilo de la reflexión sobre tal o cual obra, insertos con frecuencia en sus prólogos o apéndices. En el campo de la teoría poética durante la colonia queda aún mucho por explorar y no solo en lo relativo a tipologías o clasificaciones de estos tratados, que o bien se escribieron allá o circularon por aquella orilla. Se impone la necesidad perentoria de una atención crítica en profundidad a un corpus de escritos considerables que incluye por igual obras de retórica y poética y reflexiones puntuales sobre los géneros, de corta extensión y como defensa de lo que se va a escribir, normalmente formando parte de los paratextos. ${ }^{1}$ Es el caso que aquí nos trae, el prólogo a un poema épico en el que se aprecia la reflexión poética aplicada al género épico.

Se trata del "Prólogo" al célebre y único poema épico que escribió Bernardo de Balbuena, El Bernardo, o Victoria de Roncesvalles, 1624. No es el único texto del obispo de Puerto Rico donde reflexiona sobre teorías poéticas, pues ya con anterioridad habíamos conocido la "Carta al arcediano" y el "Compendio apologético en alabanza de la poesía" incluidos en Grandeza mexicana, 1604. Hace veinte años, Georgina Sabat nos advirtió de la necesidad de volver a estas obras menores de Balbuena dejando apuntada la importancia del prólogo bernardiano como ejemplo de la teoría poética aplicada a la épica.

Sin lugar a dudas, conviene recordar el problema general de las teorías sobre la escritura en el Renacimiento, ya que es el punto de partida sobre el que se gestarán los textos teóricos coloniales. Es Aristóteles un punto de referencia necesario pues, a través de sus ideas poéticas y retóricas, ejerció una gran influencia. Tanto la Poética aristotélica como la Epistola a los Pisones de Horacio son textos fundamentales para las discusiones teóricas renacentistas. El expansionismo que significó el Renacimiento contribuyó al impulso innovador en las obras retóricas y poéticas. Un buen ejemplo fue Juan Luis Vives quien, en su obra "De causis corruptarum artium" (primera parte de De disciplinis libri XX,

1. Lejos quedan ya, aunque siguen siendo de gran utilidad, los dos tomos de Porqueras Mayo (1986; 1989) en los que antologizan las "teorías poéticas" en el Renacimiento, Manierismo y Barroco. Un mínimo cuerpo de análisis incluiría ocuparse de los siguientes textos: Artis poeticae. Compendium (Joaquín Ayllón, c. 1755 -Ayllón, de nacionalidad ecuatoriana, vivió entre 17121767 pero su obra no fue sacada a la luz hasta el siglo XIX)-; "Discurso en loor de la poesía" (1608); Apologético a favor de D. Luis de Góngora (Juan Espinosa y Medrano, el Lunarejo, 1662); "Invectiva Apologética" (Hernando Domínguez Camargo 1675) y La Thomasiada (Diego Sáenz Ovecuri 1667). 
1531), califica de empíricos, en su observación de las reglas del arte, a Aristóteles, Quintiliano u Horacio; es decir, para Vives el arte tiene una teoría propia, abstracta, que no se corresponde en su perfección con los modelos de la Antigüedad. Sus teorías dan pie a la libertad del arte, el poeta es libre de crear porque la teoría estética es mucho más amplia de lo que los antiguos habían pensado. Dicha libertad viene a sumarse a otro postulado igualmente importante, la aparición del lector o espectador como integrante del acto de la creación literaria, la intención de deleitar se va imponiendo progresivamente al mero enseñar y así lo recoge Lope de Vega en el "Arte nuevo de hacer comedias”. Los límites de la creación no provienen solo de la retórica o preceptiva literaria, su eficacia se demuestra cuando es recibida por un público o lector.

En líneas generales, estos textos sobre la poética se guían por los tres principios retóricos de imitación, emulación y elocución. Se intentará esclarecer qué es la poesía y cuál es su función en la sociedad. Algunos, presumiblemente, intentarán defender la creación poética con justificaciones morales, no solo explicar qué es poesía o defenderla, sino ofrecer una praxis crítica. Ahí entrarían textos como los prólogos de Balbuena. ${ }^{2} Y$ aún el texto que aquí nos trae cumple también, a su modo, con el precepto de ofrecer reglas claras y precisas de cómo escribir. Con frecuencia la mayoría del corpus lo forman textos de preceptiva literaria o retórica que circulaban por colegios y universidades, pero a su lado están estos otros textos menores, por su extensión, como el de Balbuena, quien, al prologar su Bernardo, nos ofrece su breve concepción sobre la poesía épica.

La revisión de las poéticas exige una lectura comprensiva, tanto desde el punto de vista de la teoría como de su puesta en práctica, que debería atender a los siguientes objetivos: la tradición en la que se insertan y las preceptivas literarias que las mueven; el contacto o información sobre sus contemporáneos, en los casos pertinentes, analizando las posibles razones de esas citas; el nivel cultural de los artífices de estas poéticas en atención a la erudición y citas de sus textos; el seguimiento de un canon frente al desarrollo de teorías propias: cómo articula y maneja las fuentes utilizadas; el carácter especular de algunas poéticas o la revisión de la conciencia crítica que sus autores generan en algu-

2. Otro texto clave será la defensa abierta de Góngora que realizará el peruano Juan de Espinosa y Medrano en su famoso "Apologético". En la posición de ofrecer una praxis se encuentra la "Invectiva apologética" del colombiano Hernando Domínguez Camargo donde su autor adopta una postura clara y abierta frente a los letrados de su época, manifiesta su punto de vista sobre cómo es la mejor manera de hacer poesía e incluso adjunta su propio ejercicio poético. 
nos de estos textos; en suma, la combinación de planteamientos preceptivos propios y ajenos ligados a la conciencia nacionalista y/o criolla.

Balbuena muy claramente plantea tres objetivos en su prólogo: cómo entiende él lo que debe ser un poema heroico, cómo debe componerse, tanto en el aspecto narrativo como métrico, y cómo debe llegar al lector. Intención, gestación y comunicación, asimilación de los preceptistas y sus interpretaciones, composición del autor, y de este al lector, no sin antes justificar la fecha de salida de su libro y su afición a la poética y retórica desde tiempos pasados. ${ }^{3}$

Ya Aristóteles define en su Poética a la épica como imitación de las acciones nobles, sin límites temporales y en verso hexámetro; pero su subordinación a la tragedia complicó muy pronto su materialidad como género. Cuando a mediados del siglo XVI los neoaristotélicos italianos vuelven hacia los textos del estagirita no hacen sino arrojar mayores sombras a la interpretación haciendo que los límites difusos sigan creciendo. Si bien en España la primera traducción de la Poética se debe a Seijas y Tovar en 1626, dicha doctrina ya había sido propagada por Luis Alfonso de Carvallo en El cisne de Apolo (1602) y por Francisco Cascales en sus Tablas poéticas (1617), sin olvidar la Filosofía antigua poética (1596) de López Pinciano. Si hemos de hacer caso a Rodilla, "los principios de retórica y poética de Aristóteles llegaron a América en 1600 a bordo del navío La Trinidad" (1996, 35), junto a otros cargamentos de libros que burlaban una vez más las prohibiciones vigentes y cuyo tránsito analizó muy bien, en su momento, Irving A. Leonard. Es evidente que buena parte de la ilustración de Balbuena se debió a estos libros importados con independencia de las lecturas que pudo haber hecho en su viaje a la Península, especialmente entre 1606 y 1610, cuando obtiene en Sigüenza el doctorado en Teología y publica su novela pastoril: Siglo de Oro en las selvas de Erifile (1608). Su contemporaneidad con la difusión de estos preceptos indica de entrada una perfecta sincronía con la cultura de su tiempo.

Conviene detenerse, aunque sea brevemente, en los lazos de Balbuena con una leyenda y con una poética. Elige como héroe épico a su homónimo Bernardo cuya leyenda estaba consolidada en la España de entonces. ${ }^{4}$ Poco debe importarnos si existió o no Bernardo del Carpio porque su leyenda es

3. Sobre el prólogo de esta obra de Balbuena se han ocupado brevemente Pierce (254-56) y AvalleArce (89-96). Con posterioridad, Hopkins.

4. Para un análisis detenido del personaje Bernardo del Carpio remitimos a los estudios de Ratcliffe y Lázaro Niso. Sobre la épica bernárdica se recomienda la lectura del artículo de Vilà. 
más importante que su existencia. Famosa figura de las crónicas y del romancero, ${ }^{5}$ paradigma de las rencillas bélicas entre España y Francia, ${ }^{6}$ en la segunda mitad del siglo XVI, como ha estudiado Chevalier (1966), su historia inspiró libros de caballería, algunos de los cuales formaban parte de la biblioteca de don Quijote que fueron a parar a la hoguera, pero también el teatro se hizo eco de sus hazañas. En el siglo XVI Juan de la Cueva lo había llevado a las tablas en Comedia de la libertad de España por Bernardo del Carpio (1579). Elementos de la historia de Bernardo encontramos en la comedia La casa de los celos y selvas de Ardenia (1615) de Cervantes -quien lo mencionó varias veces en el Quijote-, Lope de Vega lo hizo protagonista en dos de sus obras: El casamiento en la muerte (1597) y La mocedad de Bernardo (1599-1608); y así podemos llegar al enigmático Lope Liaño (o Llano, en la edición de 1798) quien lo trata en Bernardo del Carpio en Francia (1651). Los ejemplos podrían multiplicarse pero, en suma, lo destacable es que en la literatura, además de ser el protagonista de numerosos romances, fue el tema de los poemas épicos de Nicolás Espinosa (Segunda parte de Orlando, 1555), de Francisco Garrido de Villena (El verdadero suceso de la famosa batalla de Roncesvalles, 1555), de Agustín Alonso (Historia de las hazañas y bechos del invencible caballero Bernardo del Carpio, 1585), de Luis Barahona de Soto (La Angélica, 1586), Cristóbal Suárez de Figueroa (España defendida, 1612) y aún desempeñó un papel destacado en la Lyra beroyca de Francisco Núñez de Oria (1581).

Con este plantel de precedentes que apunta al heroísmo del leonés, Balbuena inicia en edad temprana su poema épico consagrado a hechos remotos, en suma, pergeña una epopeya fantástico-medieval. Es evidente que dicha obra hay que insertarla dentro del conjunto de una serie de obras escritas a partir de 1555 que "perseguían una cierta finalidad patriótica, concretamente mediante el énfasis en las hazañas de los héroes españoles, en contraposición con los héroes percibidos como franceses del Orlando de Ariosto y Boiardo" (Dolle 474). No es nuestro propósito ahora desplegar las múltiples referencias americanas del poema de Balbuena, muy bien rastreadas por Dolle, que se conjugan con la intención patriótica española frente a injerencias extranjeras y que apuntan a España como nación elegida, incluso para la conquista del Nuevo Mundo: "En la España de los siglo XVI y XVII, cuando esta nación in-

5. Sobre el romancero y las crónicas medievales en El Bernardo se ha ocupado recientemente Zulaica.

6. La épica, como ha señalado Davis (2002), implica una conflictividad de sujetos, depende de una oposición, en este caso España y Francia. 
tenta imponer su dominio en el mundo, la función ideológica del texto consiste justamente en contribuir a defender y difundir el mito legitimador de los propósitos imperiales" (Triviños 1981, 116). En este sentido, Cortés, que tiene un protagonismo destacado en el poema épico, actúa como "libertador", no como conquistador, de los tlaxcaltecas frente a los sanguinarios aztecas.

Dejemos para otra ocasión la presencia de lo americano en el poema y volvamos al prólogo. Este poema épico, que en el decir de Menéndez Pelayo pertenecería a la modalidad novelesca o fantástica, fue un poema de gestación y desarrollo tan movidos como la vida de su creador. En enero de 1609 se decreta que se examine la obra y Mira de Amescua la aprueba el 9 de febrero en Madrid, pero el proyecto de publicación tiene que aplazarse y Balbuena seguirá puliendo lo que estimaba como su gran obra. La composición del libro, el último de su producción que ve la imprenta, requiere una aclaración: su alusión a una escritura dilatada, catorce años, "porque el tiempo, dueño de las acciones humanas, de tal manera altera y muda las cosas" (Balbuena 72). Pese a que comienza declarando que "sacar ahora a luz este libro, en alguna manera desdice de lo que en rigor toca a mi oficio y dignidad, y a la profesión de púlpito y estudios de Teología” (72), no deja de ser una declaración de bumilitas porque su intención estaba clara, tenía que "celebrar el real origen y descendencia de la excelentísima casa de Castro, una de las más calificadas de Europa” (72). Está dedicado a D. Francisco Fernández de Castro, y ahí explícitamente confiesa que, pese a tener la licencia de imprimirlo, "hasta ahora no se ha hecho por las dificultades con que de ordinario caminan las cosas que van sobre diligencia de cuidados ajenos" (71). Como en otras ocasiones en las que Balbuena se había quejado amargamente de la vida apartada de pueblos y aldeas mexicanas, exilado de las luces y del saber depositado en la capital, tampoco aquí desaprovecha la ocasión de lamentarse de su suerte en cargos eclesiásticos en zonas que le apartan del centro de cultura, y confiesa que "ha salido de nuevo al mundo de las soledades de Jamaica donde este tiempo estuvo como encantado" (71).

Enuncia desde el inicio que "todo en él es sujeto, heroico y grave, lleno de honestidad, modestia y pureza de lenguaje" (72). Cumple así uno de los preceptos de Cascales. A la pregunta de Pieiro de qué es la epopeya, le responde Castalio:

Es imitación de hechos graves y excelentes, de los quales se haze un contexto perfecto y de justa grandeza, con un dezir suave, sin música y sin bayle, ora narrando simplemente, ora introduziendo a otros a hablar. 
Dan materia al poema heroico con sus claros hechos los ilustres príncipes y cavalleros inclinados naturalmente a grandes honras. (s.p.)

A continuación hablará Balbuena del público lector distinguiendo el vulgo del docto pero acordando finalmente la utilidad de sus obra para ambos pues "quise servirles el plato con salsa, a los unos que procuren seguir los preceptos de su arte, y a los otros que si quisieren salir de su ordinario paso y entrar al fondo de las cosas, hallen senda y camino por dónde" (72). A renglón seguido se pone bajo el magisterio de Aristóteles, "siguiendo yo el que desta facultad Aristóteles nos dejó en sus obras" (73). Y añadir que esta será "breve, admirable y de varón famoso y tan llena de rastros de grandeza en la memoria de los hombres" (73). Defiende la unidad de acción y poco después enuncia lo que será el meollo poético de su Bernardo:

Lo que yo aquí escribo es un poema heroico, el cual según doctrina de Aristóteles ha de ser imitación de acción humana en alguna persona grave, donde en la palabra imitación se excluye la historia verdadera, que no es sujeto de poesía, que ha de ser toda pura imitación y parto feliz de la imaginativa. (73)

La insistencia en la imitación no es baladí, es cuestión importante en la época, la imitación de los modelos precedentes se cita con orgullo, de ahí la mención explícita a Homero y sus héroes, Agamenón, Aquiles, Ayax, Ulises, Héctor, etc., que inspirarían a Alfonso el Casto, Bernardo, Ferraguto, Galalón, Roldán, etc. Además, “el Boyardo y los que le han seguido" (Balbuena 74), inventores de las hadas y encantamiento de magos "que siendo potestades superiores, sirven de levantar la fábula y hacerla en el deleite y alegoría más vistosa y admirable" (74) porque "yo en esto seguí lo que hallé inventado" (74).7 Paralelamente excluye la historia porque no es poesía, de acuerdo a la idea aristotélica. Refiere primero el hallazgo de la materia, la inventio:

Trabajé en hallar una que, sirviendo de fundamento a mi poema, en sí misma fuese breve, admirable y de varón famoso [...] Tal me pareció la de nuestro famoso español Bernardo del Carpio, breve en su discurso, como lo son casi todas las historias de aquel tiempo; admirable por la pomposa fama con que siempre sus hechos se han celebrado de memoria en memoria hasta la nuestra; de príncipe heroico. (73)

7. Sobre el tema de lo maravilloso tenemos el detenido estudio de Rodilla (1999). 
En lo referente a la dispositio, explica que hay dos modos de contar, "uno natural, que es el histórico, y otro artificial, que es el poético" (74), de ahí la conveniencia de que en el segundo no se cuenten las cosas desde el principio, sino in medias res para que "se comience, se prosiga y acabe artificiosamente" (74).

Además insiste Balbuena en el "deleite", ecos de Horacio, pero sin que dicho deleite olvide, aunque sea ligeramente, la enseñanza moral: "Porque tocar la moralidad fuera dilatar demasiado este discurso, remito al lector que la quisiere al fin de cada libro" (76). Por último atiende el prólogo a la elocutio: "Y para mejor tejer las narraciones de un poema tan largo, sin cansar demasiado con ellas, procuré que la persona del autor hablase en él lo menos que fuese posible" (75), porque para el abad de Jamaica era muy importante "acertar con la vena del deleite para dar con ella en la de su gusto" (76) con lo que insiste en la disposición del tema y el impacto de lo maravilloso puesto en boca de terceros, para de esta manera extenderse a cosas más admirables sin perder la verosimilitud. Tampoco olvida dar sus opiniones en lo relativo a la métrica, con la que termina su prólogo.

Si estos principios son seguidos fielmente, o no, en el desarrollo del poema sería materia de otro trabajo. Ya Davis apuntaba a "una falta de correspondencia entre las ideas expresadas en el prólogo y la estructura de la obra" (2002, 142), basándose sobre todo en las opiniones de Van Horne, que han sido matizadas a posteriori por Triviños $(1980 ; 1981)$. Su emulación de los clásicos antiguos y de los modelos renacentistas italianos y españoles le llevan a un alarde más de destreza poética. Como hiciera con la pastoril, otro género privilegiado, Balbuena muestra su capacidad poética también en la épica pese a sus avatares personales, que lo llevaron por caminos no siempre cómodos y adecuados a empresa de tal naturaleza. Balbuena cierra con esta obra, la primera que inicia, el círculo de toda una trayectoria literaria que supo aunar la práctica de dos de los más destacados géneros de su tiempo: el pastoril y el épico (en menor medida la epístola poética en su canto a la capital mexicana), conjugando sus intereses literarios y su formación de hombre letrado con su condición de religioso. Su práctica literaria le convierte automáticamente en un miembro del elenco de letrados peninsulares que se escorza hacia el continente americano pues en ninguna de sus obras olvida la mención a la tierra que habita, América. Su conquista, su grandeza y su esplendor salen a relucir en todas sus obras porque, pese a sus quejas, es América el espacio en el que desarrolla su vida y ejerce de eclesiástico. 


\section{OBRAS CITADAS}

Aristóteles. Poética. Trad. Valentín García Yebra. Madrid: Gredos, 1974.

Avalle-Arce, Juan Bautista. La épica colonial. Pamplona: Universidad de Navarra, 2000.

Balbuena, Bernardo de. El Bernardo, o victoria de Roncesvalles. Ed. Martín Zulaica. 2 vols. Madrid: Ars Poetica, 2017.

Bramón, Francisco. Los Sirgueros de la Virgen sin original pecado. Ed. Trinidad Barrera. Madrid: Iberoamericana/México: Bonilla Artigas, 2013.

Cascales, Francisco. Tablas poéticas. Alicante: Biblioteca Virtual Miguel de Cervantes, 2002. 14 de abril de 2017. <http://www.cervantesvirtual.com/ nd/ark:/59851/bmc9c6w9>.

Chevalier, Maurice. L'Arioste en Espagne (1530-1650): Recherches sur l'influence du Roland furieux. Bordeaux: Féret et Fils, 1966.

Davis, Elizabeth. Myth and Identity in the Epic of Imperial Spain. Columbia (Missouri): Missouri UP, 2000.

Davis, Elizabeth. "La épica novohispana y la ideología imperial". Historia de la literatura mexicana. Vol. 2. Coord. Raquel Chang-Rodríguez. México: Siglo XXI, 2002. 129-52.

Dolle, Verena. “¿Añoranza de la metrópoli o expresión de una conciencia criolla?: El Bernardo o la Victoria de Roncesvalles de Bernardo de Balbuena”. La formación de la cultura virreinal, II: Siglo XVII. Ed. Karl Kohut. Madrid: Iberoamericana, 2004. 473-503.

Firbas, Paul, ed. Épica y colonia. Lima: Universidad Mayor de San Marcos, 2008.

Hopkins, Eduardo. "La legitimación teórica de la épica manierista en El Bernardo de Bernardo de Balbuena". Teorías poéticas en la literatura colonial. Ed. José Pascual Buxó. México: UNAM, 2012. 89-112.

Lázaro Niso, Rebeca. "La leyenda de Bernardo del Carpio y su proyección en la literatura". Cuadernos de Aleph 7 (2015): 79-95.

Marrero-Fente, Raúl. Épica, imperio y comunidad en el Nuevo Mundo: Espejo de paciencia de Silvestre de Balboa. Salamanca: Centro de Estudios Ibéricos y Americanos, 2002.

Marrero-Fente, Raúl. Poesía épica colonial del siglo XVI: historia, teoría y práctica. Madrid: Iberoamericana, 2017.

Pierce, Frank. La poesía épica del Siglo de Oro. Madrid: Gredos, 1968.

Porqueras Mayo, Alberto. La teoría poética en el Renacimiento y en Manierismo españoles. Barcelona: Puvill Libros, 1986. 
Porqueras Mayo, Alberto. La teoría poética en el Manierismo y Barroco españoles. Barcelona: Puvill Libros, 1989.

Ratcliffe, Marjorie. "Honor y legitimidad: Bernardo del Carpio en el Siglo de Oro". Edad de oro cantabrigense (Actas del VII congreso de la AISO). Coords. Anthony Close y Sandra María Fernández Vales. Madrid: Iberoamericana/Frankfurt am Main: Vervuert, 2006. 521-26.

Rodilla, María José. "La Poética de Aristóteles y la épica colonial”. La cultura literaria en la América virreinal. Ed. José Pascual Buxó. México: UNAM, 1996. 33-42.

Rodilla, María José. Lo maravilloso medieval en el Bernardo de Balbuena. México: UNAM, 1999.

Sabat de Rivers, Georgina. "Las obras menores de Balbuena: erudición, alabanza de la poesía y crítica literaria". Revista de Crítica Literaria Latinoamericana 43-44 (1996): 89-101.

Triviños, Gilberto. "Bernardo del Carpio desencantado por Bernardo de Balbuena". Revista Chilena de Literatura 16 (1980): 315-38.

Triviños, Gilberto. "Nacionalismo y desengaño en El Bernardo de Balbuena". Acta Literaria 6 (1981): 93-117.

Van Horne, John. Bernardo de Balbuena: biografía y crítica. Guadalajara (México): Imprenta Font, 1940.

Vilà, Lara. "De Roncesvalles a Pavía: Ariosto, la épica española y los poemas sobre Bernardo del Carpio". Criticón 115 (2012): 45-65.

Zulaica, Martín. "Tradición e innovación. El uso de las crónicas medievales y del romancero en El Bernardo de Balbuena. Doiro antr'o Porto e Gaia: Estudos de Literatura medieval Ibérica". Ed. José Carlos Robeiro. Porto: Estrategias Criativas, 2017. 1003-18. 